\title{
Small Business Economics: A Perspective \\ from the Netherlands
}

Roy Thurik

\section{Editors' Introduction}

In 1988, Roy Thurik was appointed as professor of small business economics at the Erasmus University in Rotterdam, The Netherlands. He was the first to be appointed to this chair, which was newly founded at the Econometric Institute of the Economics Faculty. Thurik is also head of the department of fundamental research at the Research Institute for Small and Medium-Sized Business in Zoetermeer. At the occasion of his apponntment to the editorial board of Small Business Economics: An International Journal, we asked him to translate and adapt a part of his inaugural lecture which he delivered at Erasmus University on February, 2, 1989. In this edited version he first considers the historical background of what led to the econometric approach of small business research in The Netherlands. He provides an analysis of what, in fact, constitutes small business economics, distinguishing between three levels of research. He stresses the important role the entrepreneur should play in small business research. And, finally, he provides several reasons why small business economics is a relevant and important discipline.

\section{Introduction}

Fifteen years ago there was considerable dissatisfaction within the Research Institute for Small and Medium-Sized Business in The Netherlands regarding the state of small business research. It was felt that the time was ripe for an innovative research agenda and that this new approach could contribute significantly to the stock of knowledge in the field.

The decision was made to found a working

Final version accepted on August 7, 1989.

Department of Fundamental Research

Research Institute for Small and Medium-Sized Business

2701 AA Zoetermeer, The Netherlands

and

Econometric Institute

Erasmus Unversity Rotterdam

3000 DR Rotterdam, The Netherlands group to set up quantitative model building in cooperation with the Econometric Institute of the Erasmus University in Rotterdam. The working group was immediately confronted with six basic questions:

(1) Should the concept of productivity be defined first and should differences in observed productivity be explained subsequently? Or should research be set up so that a clear definition of productivity could be expected?

(2) Should the existing statistical industrial classification be used or should a new classification system be considered as a research goal?

(3) Should research concentrate on the similarities or differences between firms?

(4) Should research first aim at the macro level? If so, what is the role of small and mediumsized business (SMB) in the domestic economy? Or should research start at the micro level; for instance, what is the role of firm size in explaining operating differences between firms?

(5) Can existing economic theory be applied or do new theories specific to small firms have to be developed?

(6) Is qualitative model building a useful tool to acquire knowledge of SMB?

Philosophic discussions of these matters are of little direct use for understanding SMB. A beginning had to be made. The decision was made to start with quantitative model building on a micro level in the retail trade.

\section{History}

In 1974 a research program consisting of the comparative analysis of the operation of individual small shops was established. Of course, the first step was to examine the appropriateness of eco- 
nomic theory. It appeared that there were hardly any economic theories relevant to our problems.' It also appeared that the specialized retail literature did not offer theories which could be empirically estimated by quantitative models.? This literature usually provided adequate but simple descriptions or anecdotal analyses. In short, the situation fifteen years ago was:

(1) There was a plea from SMB and their representative bodies for consideration of their problems based upon the paucity of scientific explanations of many phenomena. Confining ourselves to retailing we were confronted with questions like: What is the cause of scale effects in labour productivity which are often identified in comparative investigations? Why do small retail outlets fail? To what degree is retail trade a cause of inflation? What is the role of small retailing for domestic employment according to professional or vocational trade?

(2) The scientific translation of what constitutes the SMB world - and I just gave an example for the retail continent in this world - could not be readily connected to general economic theory or specialized literature. SMB research had no scientific tradition of journals and conferences of high quality, academic research positions, research networks, etc.

(3) There was no genuine scientific tradition. SMB research usually aimed at vocational training. It had no potential for external funding from large firms with the prestige connected to this source of financing. ${ }^{3}$ Small was not really beautiful yet.

(4) The appropriateness of quantitative model building was uncertain, as well as the best level to start research. Three research levels can be distinguished in the area of SMB - a micro, a meso and a macro level. They will be examined below. In view of this distinction, the question arises whether it is possible to acquire knowledge at the micro level and to apply it at higher aggregation levels, or should a SMB dimension be built directly into industry or macro models?

\section{Small business economics}

Fifteen years have elapsed since then, and a new discipline in the economic sciences has been developed, called 'small business economics'. It comprises the study of:

(1) Small firms' operations and scale effects, i.e., how and why firm behaviour depends upon firm size;

(2) Growth, entry and exit of small firms, i.e., why do different sizes exist;

(3) The role of small firms in a market environment, with a distinction between existing and new markets and with special attention for various aspects of these markets, such as concentration, competitiveness, contestability, spatial behaviour, cooperative behaviour, employment, etc.

I like to view 'small business economics' as a quantitative, theory-creating discipline within the economic sciences, which does not represent any special political interests of SMB institutes. It is not confined to the study of fixed, well-defined size classes, but instead seeks to investigate regularities dependent upon size. It is complementary to our historical orientation towards large companies.

\section{Three levels of research}

We can distinguish between three levels of economic research in the area of SMB, henceforth simply called small business. On the micro level there is the study of the operation of individual firms within a certain business type or industry. Such a study contains modules describing the process of production, organization, pricing, investment, financing, etc. Aspects like size, type of product, quality, service, production techniques and technical facilities, modes of cooperation, characteristics of sellers and buyers, competition, location, role of entrepreneur and employees will all play their parts.

On the meso level there is the study of the collective behaviour and the role of small businesses in markets. For instance, what is the behaviour of the average small firm vis-à-vis the average large firm in a given line of business? Such a study contains modules on costs, pricing, entry and exit, size distribution, employment, type of production, etc. Aspects such as the business cycle, life cycle of business types or products, 
market shares, cooperative or competitive behaviour, imports and exports, technological or intellectual development, spatial behaviour and infrastructure and regulations will all play their parts.

On the macro level there is the study of the collective behaviour and the role of small businesses in entire industries or on a national level. This level of research is comparable to that of the meso level, in that it aims at a higher level of aggregation. However, relationships across business types can also be of relevance.

It is the objective of scientific research to provide us with a theoretical framework within which we can understand and explain phenomena in order to evaluate and predict the effects of decisions and developments. One of the basic elements of small business research pertains to the role of the entrepreneur. That is why I shall devote the next section to examine this element. ${ }^{4}$

\section{The role of the entrepreneur}

If we want to understand the essence of small business, we have to penetrate into the micro level, i.e., into the level of the firm itself. The role of the entrepreneur is of supreme interest in small business research. In The Netherlands, about 90 per cent of firms employing less than 100 persons consists of firms employing less than 10 people. One-half employ no work force at all.

Management in large firms is usually complex with considerable turnover. Sometimes there are staff departments with far-reaching responsibilities. It is of vital concern to gather knowledge about the motivation, objectives, modus operandi and character of the entrepreneur. This is not only fundamental for model building at the micro level, but also important for tracing and understanding scale effects, for explaining the differences between large and small companies and to improve model building at the meso level.

Considerable research has been done concerning the character and role of the entrepreneur. This research looks at entrepreneurship from many perspectives. For example, there exists an important body of research from a psychological perspective focusing on the personality characteristics of entrepreneurs. ${ }^{5}$ There is a body of socioeconomic research on the role of small business in the domestic economy while taking into account the so-called entrepreneurial characteristics. ${ }^{6}$ There is body of research clarifying the entrepreneurial

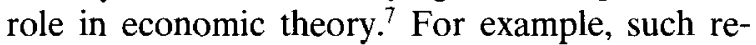
search focuses on how general equilibrium theory can be reconciled to the fact that business-(wo) men are endowed with human characteristics such as talents and shortcomings, ${ }^{8}$ memory and experience, ${ }^{9}$ and risk awareness. ${ }^{10}$

There are many more specific approaches to research on the characteristics of entrepreneurs. For example, on the issues of bankruptcy and risk-signaling procedures, " start-ups and employment, ${ }^{12}$ family members who, while cooperating, influence business, ${ }^{13}$ technological change, inventions, their application and diffusion, ${ }^{14}$ female entrepreneurship, ${ }^{15}$ and idealistic entrepreneurship. ${ }^{16}$ Moreover, there are general empirical studies on small business ${ }^{17}$ and there is an abundance of normative, educational messages. ${ }^{18}$

I do not see any characteristic features which are typically assigned to entrepreneurs and not to non-entrepreneurs. There are just too many entrepreneurs, and their activities are much too heterogeneous. Small businesses have managed to penetrate all strata of the economy, all stages of the production chain and all intellectual levels. From bicycle manufacturers to software advisors, from roof thatchers to beauty specialists, from crude-oil dealers to computer-aided moulding manufacturers.

Even if there are any differences in population characteristics, it still is doubtful whether this will elucidate our impression of the small-business (wo)man. Besides, we are confronted with the problem of defining entrepreneurship or independence. A juridical/economic proverb will not be of any use here. What to think of the director of small limited-liability corporations (usually implicitly being the 'owner'), of franchise formulae, of part-time independence and of the various other forms of quasi-independence which are manifested within large companies or institutions?

On the micro level, the role of entrepreneurs in small businesses is of vital importance. So far, our resourcefulness regarding the ability to integrate the entrepreneur in our econometric models has been insufficient.

For the time being, we could perhaps add to our search for entrepreneurial characteristics by investigating the motives which lead to independence. Which factors generate the choice for 
entrepreneurship? I distinguish four clusters of motives:

(1) The desire for independence, status and development of one's own talents. These non-material motives sometimes dominate material motives: 'One does not engage in business because of profits, yet one requires profits in order to stay in business' ${ }^{19}$

(2) Entrepreneurship is the availability of options, such as those regarding profit, independence, power, etc. The profile of the various options is not that important. An entrepreneur is inclined to underestimate the risk factors. An entrepreneur is optimistic. This corresponds to the image of an entrepreneur as searching for new combinations ${ }^{20}$ or as being the 'inquiring person'. ${ }^{21}$

(3) Coincidences, such as a good idea (a computer programme), the invention of a good product (paper clip) or the adherece to certain political or philosophical trends, or the inability to air one's ideas by any means other than by starting an enterprise. ${ }^{22}$

(4) Various other reasons. First, there is the phenomenon of hereditary succession, one of the most traditional recruitment methods for entrepreneurship.

Secondly, there is the syndrome of stagnation in one's career, or, even worse, unemployment. This is the so-called 'escape hypothesis', which also has been detected at the macroeconomic level, i.e., in times of economic decline one escapes into independence. $^{23}$

The third reason is the antipathy $v i s-\dot{a}$-vis hierarchic regimes, the fear of specialization and monotony. This is complementary to the first cluster of motives.

The fourth reason is to be able to escape from the fiscal transparency which one is confronted with when one is employed. This may lead to part-time independence.

As a fifth reason I detected the thesis of 'social marginality'. The isolated and therefore miserable social status of refugees, immigrants and ethnic minorities provides the pushing agent' into independence. ${ }^{24}$

One could also add structure to the search for entrepreneurial characteristics by investigating the motives to leave an existing business. ${ }^{25}$

\section{Particular characteristics}

Small business economics is a rather complex discipline. However, one has to bear in mind that research with respect to small businesses generates elements which one will not, or only up to a certain degree, find in other disciplines within the economic sciences. Precisely these elements, however, generate the attractive features of research When outlining these attractive features, I shall illustrate some of the aspects of our research programme.

On the whole, the uniqueness of larger companies is not found in smaller firms. Growth often is accompanied by diversification. In other words, growth depends on specific situations. Hence, one is able to discern clusters of small firms which display a certain degree of homogeneity. Due to their inherent simplicity, the description of smaller firms turns out to be less complicated than that of larger firms.

One can find all elementary mechanisms which are of importance to the economy, such as production, objectives, markets, uncertainties, etc., in the sphere of small firms too.

In many cases, there will be a pivotal individual in a smaller company, who is able to give a profound account of the production process, the company's objectives and other restrictions and opportunities. Although there are many obstacles due to pressure of work, to an abundancy of questionnaires to be filled out, and also to the limited confidence in empirical findings, this pivotal individual turns out to be a good source of information. In brief, the smaller firm appears to be an attractive unit for research purposes, due to its comparability, surveyability and accessibility. Conducting surveys of small firms might enable the re-establishment and improvement of relations among the various disciplines in business administration and business economics which have been dislinked in the course of time. Most of the theoretical knowledge in the economic sciences is based upon the study of large companies. Not only will the explicit examination of small firms be 
complementary to this knowledge, it might also have greater implications beyond small firms.

The study of small firms is tailored to econometric research methods, since a considerable body of data consisting of well-described and easily comparable enterprises is available. This enables the application of a variety of techniques and methods at the micro level to achieve new and distinctive results. For example:

(1) Nonlinear estimation techniques which, time and again, are of a continuously significant influence to the valuation of parameters in nonlinear or simultaneous equations. ${ }^{26}$

(2) 'Switching-regime' models which can be applied if one cannot determine in advance whether there is excess demand or excess supply when explaining differences in floorspace productivity. ${ }^{27}$

(3) The application of econometric techniques concerning the analysis of panel data. ${ }^{28}$

(4) Concepts regarding queueing theory to provide a basis for labour cost relations. ${ }^{29}$

Combining econometric techniques with small business research is still in its infancy. I harbour the though that not only small businesses will benefit from this, but that it will also work in favour of the evaluation of these techniques: advanced econometric techniques are based upon well-specified models and a large number of observations. As it is, small firms are numerous, which enables the elimination of aggravating heterogeneity. There, typically exists, a sufficient number of observations within any given line of business to econometrically investigate certain phenomena.

Apart from these methodological attractions of 'small business economics' there are other attractive features.

There are increasing signs of interest by politicians and the mass media concerning small businesses. This is by no means entirely due to the dominating presence and versatility of small businesses, but also to the expectations regarding the role of small business concerning innovation, growth and employment. Dutch policymakers exhibit an undeniable curiosity concering tomorrow's developments. This explains that both fundamental and more risk-bearing small business research in The Netherlands is not only financed by the Ministry of Education and Sciences, but also to a large extent by the Ministry of Economic Affairs. This creates the opportunity to conduct large-scale research programmes.

Obviously, this favourable starting point can create a scientific tension, since standards of policymaking and science do not always correspond.

Research using small business data is an excellent application for quantitative research. One has to consider, however, whether this research is also of any use for these small businesses. Taking into account the amount of newly acquired knowledge and the fact that this knowledge has its impact on applied research concerning policy and management, I am convinced that this is the case.

Our research programme is based upon the study of individual outlets in the retail trade. It is not my intention to illustrate international developments regarding this matter. I only want to reveal what has been achieved in The Netherlands. The causal research framework is depicted in Figure 1.

Figure 1 shows three clusters of variables to be explained - price variables, cost variables and turnover variables. Of course, there are other decision variables, such as assortment composition, service level, stock level, organization of labour, etc. These variables are assumed to be exogenous for ease of exposition, which by no means implies that these variables have been generated independently from other variables in the model during the period of observation. Furthermore, for certain areas competitive ideas are still maintained, such as for price explanations ${ }^{30}$ and for the relation between sales and costs related to floorspace. ${ }^{31}$

I shall give some examples of the results of our research on retailing:

(1) A theoretical foundation of scale effects in the retail trade and of the role of trading hours and labour organization has been established..$^{32}$ In addition, this theoretical foundation helps to explain the failure of small outlets in retail trade. ${ }^{33}$

(2) The empirical framework used to explain 


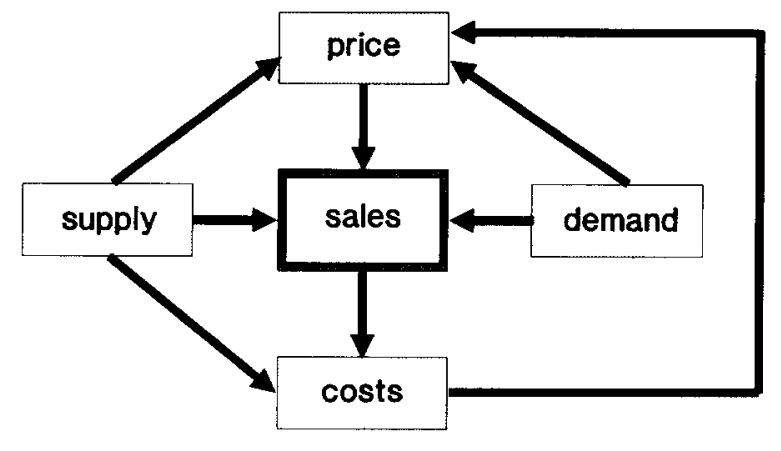

Fig. 1. Causal scheme micro research in retailing.

differences between labour productivity appears to have broad applications. The fact that it can be used both in the case of small grocery stores employing a staff of about 5 and in the case of hypermarkets with an average manpower of 250 illustrates its wide applicability. ${ }^{34}$

(3) The causal scheme of Figure 1 provided the framework to carry out extensive research regarding the influence of environmental factors on labour productivity. ${ }^{35}$

(4) By 'nesting' the models in this scheme it can be tested whether entrepreneurial behaviour can be explained in terms of maximizing profits, of maximizing turnover or of some combination. ${ }^{36}$

(5) In order to investigate the complexity of supply and demand factors which influence turnover, extensive analyses have been undertaken. The difficulty here is caused by the fact that demand factors are only important if there is sufficient supply and that expansion of supplies only makes sense when there is sufficient demand. ${ }^{37}$ Although these restrictions are obvious, their consequent implementation in quantitative models is very complicated, especially if one also integrates the price factor. As is illustrated by the causal scheme, price is also influenced by demand and supply factors. ${ }^{38}$

Many of the arrows in the causal scheme of Figure 1 have been empirically tested for many types of business, e.g., shop types, in the retail trade.

The scheme is a starting point for a micro model in other parts of the commercial services, such as wholesale trade and the hotel and catering sector. ${ }^{39}$

Small businesses usually do not have staff services at their disposal. Therefore, advice by external experts becomes necessary, with accountants playing a major part when it comes to nontechnical advice. In their advisory practice, they are in need of the findings of econometric micro research. A business diagnosis system is created by converting these findings into a functional instrument for their practice. This involves the construction of a multidimensional performance profile of each individual firm out of a cluster of comparable firms, with corrections carried out for the influence caused by individual differences within the cluster. There are examples in various business types which illustrate the useful application of these theory- and model-building activities, such as the butcher's trade, pharmacies, do-it-yourself shops and supermarkets. Outside of retail trade, first steps have been made in the printing industries, flower-exporting business and the tourist trade.

There are advanced plans to upgrade this business diagnosis system to achieve a modern, decision-supporting system, which pays attention to the interaction between factors which are easily and factors which are not easily measurable and to the interaction between utilizer and system. The fact that a decision-supporting system can provide a direct link between designer and utilizer of econometric research is very attractive, indeed.

The meso level is an attractive research level. Here, one is not confronted with the awkward individual characteristics of micro research or the elusive abstraction of macro research. Moreover, one is able to construct time series, such as, for example, covering a period of 20 years of the average cost and profit structure of dancing schools, wholesalers in plane-glass sheets, engineering works, etc. This so-called 3rd or 4th digit level is of substantial interest, since it enables the analysis of reasonably homogeneous markets.

The discrepancy between institutions and functions at this level of aggregation is acceptable. Or, simply stated, business types are defined in such a way that one can expect that all businesses of a given line of business are roughly 
selling the same goods or services and that these goods or services are not sold on a large scale by businesses of other types. From the datatechnical point of view it is interesting because time series of many markets can be compared.

We managed to construct a data bank which gives reason to be optimistic about prospective results. Within this particular discipline of the economic sciences, which has been variously categorized under the label of 'industrial economics', 'industrial organization' or 'market theory', little attention has been paid yet to the role of small enterprises in markets. Recently, however, this has changed, due to the interest in topics such as the application and distribution of inventions, ways of cooperating horizontally and vertically, entry and exit and the consequences of regulatory policies.

For example, in a recent study of the literature which we conducted in the field of empirical explanations of average prices and profit margins within markets, hardly any studies were found considering the effect of average business size. ${ }^{40}$ This explains why the questions mentioned below are important in small business economics:

(1) What exactly is the role of small enterprises in markets? ${ }^{41}$ First attempts to answer this question have been made using the concept of 'dynamic complementarity' between small and large firms. ${ }^{42}$ This concept is based upon an analysis of the relative strengths and weaknesses between small and large firms; the concept distinguishes between different roles of small and large enterprises across the various stages of the life cycle of a certain market.

(2) What exactly can be gained from a systematic partitioning of small and large firms when one studies market-related phenomena? ${ }^{43}$ There are apparently only a small number of examples which utilize a systematic partitioning to conduct a solid analysis. ${ }^{44}$ The findings of such analyses might be able to shed light in answering the first question.

(3) How can the size class distribution of firms be explained? Although, this question has been asked before, there is a paucity of empirical evidence to support any of the hypothesized explanations. ${ }^{45}$ Clearly, the explanation of the market share of small businesses is imbedded in that of the entire size class distribution.

As a matter of course, these three questions are strongly related. Within our research programme, we operate with a causal scheme, which provides the basis for meso research. A recapitulation is given in Figure 2.

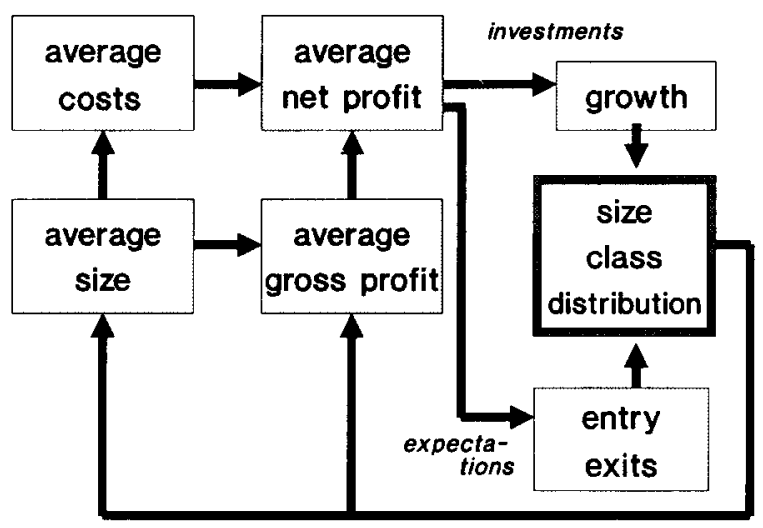

Fig. 2. Causal scheme meso research.

This scheme is more tentative than the one used in micro research. I have left out many important effects, such as demand fluctuations, input costs, life cycle, technological development, forms of cooperative behaviour, etc. Several aspects, however, already have an empirical foundation. Since further research is needed to detect its applicability, I shall not proceed to discuss the causal scheme. In brief, 'small business economics' at the meso level is fascinating, We are operating in the existing discipline of industrial economics, while new questions are brought forward. Concepts such as 'dynamic complementarity' and 'life cycle of markets' need to be supplemented by empirical research. There is an abundance of interesting and new data which also econometricians with their method-oriented mind can make use of. Finally, the meso level can act as a linking agent between micro and macro research. Ideas or findings generated at the micro level can be implanted or tested on the meso level, whereas the meso level provides an ideal laboratory for entire industries, i.e., the macro level. 


\section{Conclusion}

In the analysis of economic phenomena either within or across industries there is room for integrating the role of small business. This contribution can be made by aggregation or generalization of the findings at the meso level, which again are partly based upon analyses at the micro level.

The Netherlands has a long history in macro model building. A recent discussion among Dutch macro-economists considered the future of econometric model building at the macro level, and considered how best to improve this model building. The explicit integration of scale effects, however, was not mentioned. I am convinced that improvements in this respect are possible. In particular, I have in mind the role which small businesses play in certain areas such as wage structure, employment or investments. The dissection of macro prognoses into a small business component and a remaining component is a traditional practice in The Netherlands. ${ }^{46}$

Finally, there is much concern in The Netherlands for the calculation of regulatory effects, decomposed into effects for small and large businesses. ${ }^{47}$ If anywhere in the world there is a solid foundation for studying scale effects in both macro and sectoral models, it most certainly has been in The Netherlands. There is a strong tradition of macro-econometric model building; groups of econometricians specialized in small business research exist; Dutch policymakers show concern and the required research apparatus is available.

\section{Notes}

I See Nooteboom (1980) for a discussion of neoclassical behavioural and managerial approaches and their significance for retail research.

2 This literature comprises Journal of Retaling, Journal of Marketing, etc. Later to be followed by International Journal of Retaling, Service Industries Journal, etc.

See Davis, Hills and Laforge (1985).

4 In my original lecture I also address other problems which students of small businesses may encounter and which might be of interest for a wide audience. I deal with general methodological issues, with various types of scale effects and with an example from retailing (the difficult confrontation between economics concepts and real world problems).

5 See, for instance, Kets de Vries (1977), McClelland (1961) or Brock and Evans (1986), page 40, for a survey.
- See Pompe (1980) and Geeraerts, Ten Have and Romme (1985) for literature surveys.

7 See Haathi (1987) or Hébert and Link (1989) for literature surveys. Also, see Baumol (1968).

$\checkmark$ See, for instance, Lucas (1978).

" See Brock and Evans (1986) and Rees and Shah (1985).

1" See Kihlstrom and Laffont (1975) and De Wit and Van Winden (1988).

"See Van der Linden, Waterlander and Van der Wijst (1988) for a literature survey.

i2 See Birch (1979) and (1987) and his followers.

13 Some Dutch evidence is described in Meijer, Braaksma and Van Uxem (1984).

14 See, for instance, Rogers (1983), Kleinknecht (1987) and Docter and Stokman (1987).

${ }^{15}$ Some Dutch evidence is described in Zwaard and Meijer (1988) and European evidence in Donckels and Meijer (1986).

16 Which may readily turn into environmental entrepreneurship.

17 Examples for The Netherlands are Walravens and Zwaard (1988) and Van den Tillaart, Van der Hoeven, Van Uxem and Van Westerlaak (1981).

is To be found in journals like Journal of Small Business Management, American Journal of Small Business and Entrepreneurship.

14 See Nooteboom (1987b).

20 See Schumpeter (1961).

21 Geeraerts, Ten Have and Romme (1986) refer to Kelly (1963).

22 For instance, idealistic enterprising in environmental issues or products.

23 Nooteboom (1987a). The 'escape hypothesis' may evolve into the 'persistence hypothesis'. One sticks to one's independence in bad times, one hoards one's efforts with an option on better times. Responsibility for employees may strengthen this effect.

-4 See Nooteboom (1987a, page 18).

Is See Bögenhold (1987).

2 See Thurik (1984).

27 See, for instance, Kooiman, Van Dijk and Thurik (1985) and Bode, Koerts and Thurik (1988, 1990).

28 See, for instance, Thurik and Van der Hoeven (1989), Van Dalen, Koerts and Thurik (1989b).

2y See, for instance, Nooteboom (1982) and Frenk, Thurik and Bout (1989).

3.) Compare Bode, Koerts and Thurik (1986) and Bode, Koerts and Thurik (1990).

31 Compare Nooteboom (1980) and Thurik (1984).

32 See Nooteboom $(1980,1982)$.

3.3 See Nooteboom (1986).

34 See Thurik (1984).

35 See Nooteboom (1980) and Thurik (1984).

36 See Thurik and Koerts (1985).

${ }^{37}$ See Kooiman, Van Dijk and Thurik (1985), Bode, Koerts and Thurik (1988) and Van Dalen, Koerts and Thurik (1988a)

38 See Bode, Koerts and Thurik (1990).

${ }^{34}$ Currently, one of our researchers is investigating whether 
the causal scheme and its implications can also be utilized concerning Japanese retail trade.

411 See Thurik and Van der Hoeven (1989).

4 Concentration and its consequences regarding behaviour have been one of the traditional topics within industrial economics.

t2 For references, see Nooteboom (1987a), especially note 59 on page 35 .

4.3 It has been understood long ago that a business type is more than just a homogeneous plasma of similar firms. The issue here is that the partitioning between large and small businesses can contribute considerably in explaining certain phenomena.

it See, for example, Thurik and Van der Hoeven (1989), Verbruggen and Van der Tuin (1988) and Kleijweg (1988).

${ }^{4}$ See, for example, ljiri and Simon (1977). Scherer (1980) and Brock and Evans (1989).

th. Short- and medium-term prognoses by the Research Institute for Small and Medium-Sized Business. See also: Research Institute for Small and Medium-Sized Business (1989).

4 See Verbruggen and Van der Tuin (1988), Verhoeven (1986), etc.

\section{References}

Baumol, W. J., 1968, 'Entrepreneurship in Economic Theory', American Economic Review 58, 64-71.

Birch, D. L.. 1979, The Job Generation Process, Cambridge, MA: MIT Press.

Birch, D. L., 1987, Job Creation in America, New York: Free Press.

Bode, B., J. Koerts and A. R. Thurik, 1986, 'On Storekeepers' Pricing Behaviour,' Journal of Retailing 62, 63-74.

Bode, B.. J. Koerts and A. R. Thurik, 1988, 'On the Measurements of Retailmix Marketing Instruments in the Presence of Different Economic Regimes,' International Journal of Research in Marketing 5.107-123.

Bode, B., J. Koerts and A. R. Thurik, 1990, 'Market Disequilibria and Small Retail Store Pricing,' Small Business Economics 2, 45-57.

Bögenhold, D., 1987, 'Selbständige im Beschäftigungssystem,' in: Bildung und Beschäftigung, Göttingen: Schwartz.

Brock, W. A. and D. S. Evans, 1986, The Economics of Small Businesses, New York: Holmes and Meier.

Brock, W. A. and D. S. Evans, 1989, 'Small Business Economics,' Small Business Economics 1, 7-20.

Dalen, J. van J. Koerts and A. R. Thurik, 1989a, 'Disequilibrium in Dutch Detailing: the Impact of Demand Factors', Kwantitatieve Methoden 30, 5-20.

Dalen, J. van, J. Koerts and A. R. Thurik, 1989b, An Analysis of Labour Productivity in Wholesaling Using Panel Data and Allowing for Heteroskedasticity, Research Report 8903/A, Erasmus University Rotterdam.

Davis, D. C., G. E. Hills and R. W. LaForge, 1985, 'The Marketing/Small Enterprise Paradox, a Research Agenda,' International Small Business Journal 3, 31-42.
Docter, H. J. and C. T. M. Stokman, 1978, Diffusie van Innovaties: Met Kennis Meer Kans, Zoetermeer: Research Institute for Small and Medium-Sized Business.

Donckels, R. and J. N. Meijer (eds.), 1986, Women in Small Business: Focus on Europe, Assen: Van Gorcum.

Frenk, J. B. G., A. R. Thurik and C.A. Bout, 1989, Labour Costs and Queueing Theory in Retailing, Research Report 8912/A, Erasmus University Rotterdam.

Geeraerts, G., K. ten Have and S. Romme, 1986, Determinanten van Ondernemerschap, Tilburg: IVA.

Haahti, A. J., 1986, 'A Note on Theories of Entrepreneurship and Theories of Small Business Interface;' mimeo, Helsinki School of Economics.

Hébert, R. F. and A. N., Link, 1989, 'In Search of the Meaning of Entrepreneurship,' Small Business Economics $1,39-49$.

Ijiri, Y. and H. A. Simon, 1977, Skew Distributions and the Sizes of Business Furms, Amsterdam: North Holland.

Kelly, G. A., 1963, A Theory of Personality, New York: Norton.

Kets de Vries, M. F. R., 1977, 'The Entrepreneurial Personality: A Person at the Crossroads', Journal of Management Studies, 34-57.

Kihlstrom, R. E. en J.-J. Laffont, 1979, 'A General Equilibrium Entrepreneurial Theory of Firm Formation Based on Risk Aversion,' Journal of Political Economy 87, 719-748.

Kleinknecht, A., 1987, Industriële Innovatie in Nederland, Assen: Van Gorcum.

Kleijweg, A. J. M., 1988, Een Twee-Grootteklassensectormodel voor Omzet, Marge, Kosten en Aantal Vestigingen in de Detailhandel in Voedings- en Genotmiddelen, Researchpublikatie no. 24, Zoetermeer: Research Institute for Small and Medium-Sized Business.

Kooiman, P., H. K. Van Dijk and A. R. Thurik, 1985, 'Likelihood Diagnostics and Bayesian Analysis of a Micro-Economic Disequilibrium Model for Retail Services', Journal of Econometrics 29, 121-148.

Linden, J. van der, E. C. Waterlander and D. van der Wijst, 1988, Risicosignalering, Researchpublikatie no. 21, Zoetermeer: Research Institute for Small and MediumSized Business.

Lucas, R., 1978, 'On the Size Distribution of Business Firms', Bell Joumal of Economics 9, 508-523.

McClelland, D. C., 1961, The Achieving Society, Princeton: Van Nostrand.

Meijer, J. N., R. M. Braaksma and F. W. van Uxem, 1984, De Meewerkende Echtgenote in het $M K B$, Zoetermeer: Research Institute for Small and Medium-Sized Business.

Nooteboom, B., 1982, 'A New Theory of Retailing Costs,' European Economic Review 17, 163-186.

Nooteboom, B., 1986, 'Costs, Margins and Competition, Causes of Structural Change in Retailing', International Journal of Research in Marketing 3, 233-242.

Nooteboom, B., 1987a, 'Doen en Laten van Het MKB,' in: $O p$ Maat van het Midden- en Kleinbedriff (deel II, preadviezen), The Hague: WRR.

Nooteboom, B., 1987b, Oude en Nieuwe Theorie in Onderzoek van het $M K B$, Zoetermeer: Research Institute for Small and Medium-Sized Business. 
Pompe, J. H., 1980, De Kleine Middenstand in Nederland, Deventer: Van Loghum Slaterus.

Rees, H. and A. Shah, 1985, 'An Empirical Analysis of SelfEmployment in the U.K., Journal of Applied Econometrics 1,95-108.

Research Institute for Small and Medium-Sized Business, 1989, The State of Small Business in The Netherlands, Zoetermeer: Research Institute of Small and Medium Sized Business.

Rogers, E. M., 1983, Diffusion of Innovations, New York: Free Press.

Scherer, F. M., 1980, Industrial Market Structure and Economic Performance, Boston: Houghton Mifflin.

Schumpeter, J. R., 1961, The Theory of Economic Development, New York: Oxford University Press.

Thurik, A. R., 1984, Quantitative Analysis of Retail Productivity, Delft: Meinema.

Thurik, A. R. and J. Koerts, 1985, 'Behaviour of Retail Entrepreneurs', Service Industries Journal 5, 335-347.
Thurik, A. R. and W. H. M. van der Hoeven, 1989, 'Manufacturing Margins: Differences between Small and Large Firms,' Economics Letters 29, 353-339.

Tillaart, H. J. M. van den, H. C. van der Hoeven, F. W. van Uxem and J. M. van Westerlaak, 1983, Zelfstandig Ondernemen, The Hague/Nijmegen: EIM/ITS.

Verbruggen, J. P. and J. van der Tuin, 1988, 'Algemeen Economische Politiek en MKB', ESB, June 1, 517-522.

Verhoeven, W. H. J. et al,, 1986, De Effecten van Lastenverlichting, Zoetermeer: Research Institute for Small and Medium-Sized Business.

Walravens, A. and A. Zwaard, 1985, Zelfstandig Werken en Ondernemen in Middelgrote en Kleine Ondernemingen, Zoetermeer/Delft: RISMB/DUP.

Wit, G. de and F. van Winden, 1988, An $M$-sector, $N$-group Behavioral Model of Self-Employment, Research Memorandum 8815, University of Amsterdam.

Zwaard, A. B. and J. N. Meijer, 1988, 'Ondernemerschap van Vrouwen Is Anders,' RISMB Bulletin 5, 16-22. 